\title{
Alkyl Methyl Imidazolium Based Ionic Liquids at Au(111) Surface: Anions and Alkyl chain Cations Induced Interfacial Effects
}

\author{
Shanmugasundaram Kamalakannan, ${ }^{\dagger}$ Muthuramalingam Prakash,,${ }^{* \dagger}$ Muneerah Mogren Al-Mogren, ${ }^{\$}$ \\ Gilberte Chambaud, ${ }^{\ddagger}$ Majdi Hochlaf* \\ ${ }^{\dagger}$ Department of Chemistry, SRM Institute of Science and Technology, Kattankulathur 603203, Tamil \\ Nadu, India \\ $\$$ Chemistry Department, Faculty of Science, King Saud University, PO Box 2455, Riyadh 11451, \\ Kingdom of Saudi Arabia \\ *Université Paris-Est, Laboratoire Modélisation et Simulation Multi Echelle, MSME UMR 8208 CNRS, \\ 77454 Marne la Vallée Cedex 2, France
}


Table S1. Löwdin charge transfer analysis of $\left[\mathrm{C}_{n} \mathrm{MIm}\right]^{+}(\mathrm{n}=0,1,2,4,6,8,10)$ at the gas phase and at the solid-liquid interface.

\begin{tabular}{|c|c|c|c|}
\hline \multicolumn{2}{|c|}{ Gas phase } & \multicolumn{2}{c|}{$\left[\mathrm{C}_{n} \mathrm{MIm}\right]^{+} @ \mathrm{Au}(111)$ surface } \\
\hline$n$ & {$\left[\mathrm{C}_{n} \mathrm{MIm}\right]^{+}$} & {$\left[\mathrm{C}_{n} \mathrm{MIm}\right]^{+}$} & $\begin{array}{c}\text { Charge of the } \\
\mathrm{Au}(111) \text { surface }\end{array}$ \\
\hline 0 & 1.00 & 1.24 & -0.24 \\
\hline 2 & 1.00 & 1.32 & -0.32 \\
\hline 4 & 1.00 & 1.35 & -0.35 \\
\hline 6 & 1.00 & 1.72 & -0.72 \\
\hline 8 & 1.00 & 1.91 & -0.91 \\
\hline 10 & 1.00 & 2.12 & -1.12 \\
\hline
\end{tabular}


Table S2. Löwdin charge transfer analysis of $\left[\mathrm{C}_{n} \mathrm{MIm}\right]^{+}[\mathrm{X}]^{-}\left(\mathrm{n}=0,2,4,6,8,10 ; \mathrm{X}=\mathrm{Cl}, \mathrm{PF}_{6}, \mathrm{TFSA}\right)$ at the gas phase and solid-liquid interface.

\begin{tabular}{|c|c|c|c|c|c|c|c|}
\hline \multicolumn{4}{|c|}{ Gas phase $\left[\mathrm{C}_{\mathrm{n}} \mathrm{MIm}\right]^{+}[\mathrm{X}]^{-}$} & \multicolumn{4}{|c|}{$\left[\mathrm{C}_{\mathrm{n}} \mathrm{MIm}\right]^{+}[\mathrm{X}]^{-} @ \mathrm{Au}(111)$ surface } \\
\hline $\mathrm{X}$ & $\mathrm{n}$ & {$\left[\mathrm{C}_{\mathrm{n}} \mathrm{MIm}\right]^{+}$} & {$[\mathrm{X}]^{-}$} & {$\left[\mathrm{C}_{\mathrm{n}} \mathrm{MIm}\right]^{+}$} & {$[\mathrm{X}]^{-}$} & $\begin{array}{l}\text { Total charge of } \\
{\left[\mathrm{C}_{\mathrm{n}} \mathrm{MIm}\right]^{+}[\mathrm{X}]^{-}}\end{array}$ & $\begin{array}{c}\text { Charge of the } \mathrm{Au}(111) \\
\text { surface }\end{array}$ \\
\hline \multirow{6}{*}{$\mathrm{Cl}$} & 0 & 0.51 & -0.51 & 0.99 & 0.47 & 1.47 & -1.47 \\
\hline & 2 & 0.47 & -0.47 & 1.27 & 0.53 & 1.80 & -1.80 \\
\hline & 4 & 0.49 & -0.49 & 1.38 & 0.73 & 2.11 & -2.11 \\
\hline & 6 & 0.48 & -0.48 & 1.99 & 0.72 & 2.71 & -2.71 \\
\hline & 8 & 0.48 & -0.48 & 1.68 & 0.80 & 2.48 & -2.48 \\
\hline & 10 & 0.48 & -0.48 & 2.04 & 0.72 & 2.76 & -2.76 \\
\hline \multirow{6}{*}{$\mathrm{PF}_{6}$} & 0 & 0.51 & -0.51 & 1.00 & -0.70 & 0.29 & -0.29 \\
\hline & 2 & 0.61 & -0.61 & 1.10 & -0.64 & 0.46 & -0.46 \\
\hline & 4 & 0.56 & -0.56 & 1.09 & -0.57 & 0.52 & -0.52 \\
\hline & 6 & 0.60 & -0.60 & 1.38 & -0.63 & 0.75 & -0.75 \\
\hline & 8 & 0.60 & -0.60 & 0.94 & -0.62 & 0.32 & -0.32 \\
\hline & 10 & 0.50 & -0.50 & 0.98 & -0.63 & 0.35 & -0.35 \\
\hline \multirow{6}{*}{ TFSA } & 0 & 0.50 & -0.50 & 0.77 & -0.37 & 0.39 & -0.39 \\
\hline & 2 & 0.53 & -0.53 & 0.83 & -0.60 & 0.23 & -0.23 \\
\hline & 4 & 0.42 & -0.42 & 0.90 & -0.55 & 0.34 & -0.34 \\
\hline & 6 & 0.52 & -0.52 & 1.25 & -0.61 & 0.64 & -0.64 \\
\hline & 8 & 0.52 & -0.52 & 1.47 & -0.62 & 0.85 & -0.85 \\
\hline & 10 & 0.52 & -0.52 & 1.60 & -0.62 & 0.98 & -0.98 \\
\hline
\end{tabular}



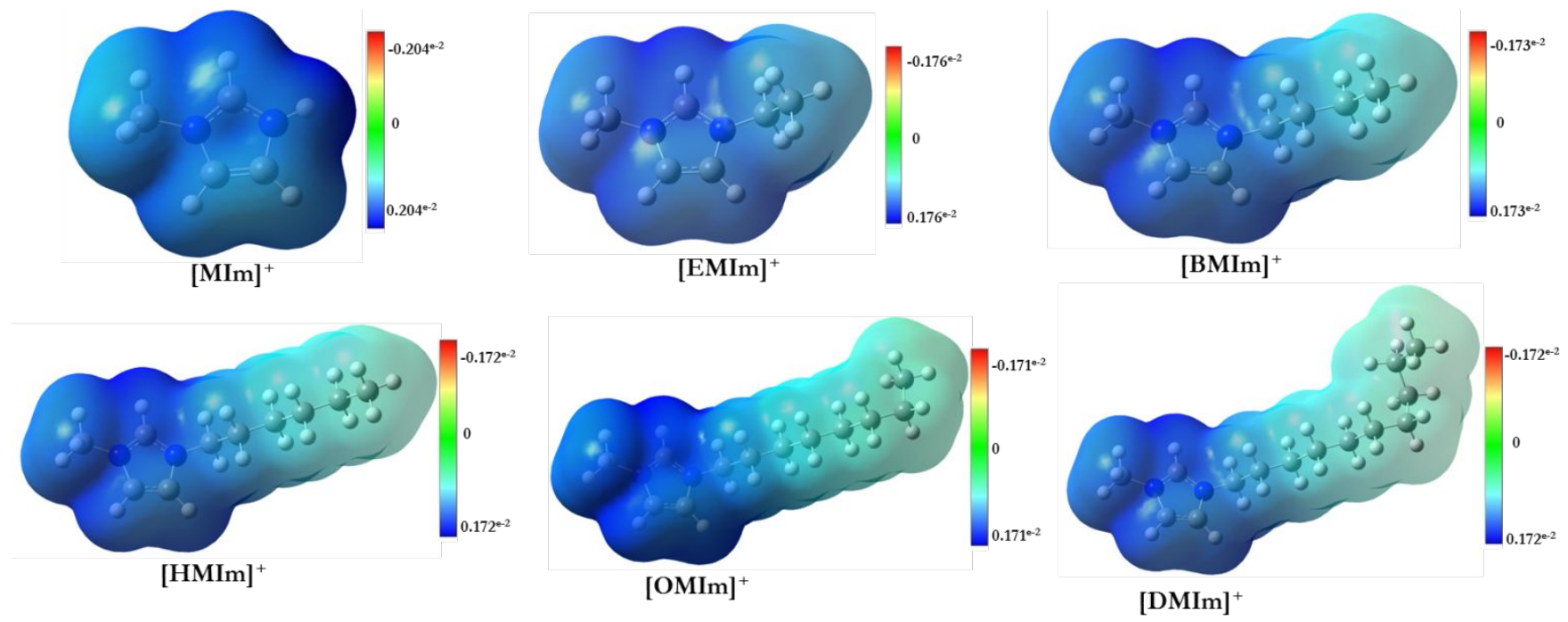

Figure S1. Electrostatic potential (ESP) of $\left[\mathrm{C}_{\mathrm{n}} \mathrm{MIm}\right]^{+}$cation in gas phase mapped at the van der Waals $(\mathrm{vdWs})$ surface (electron-density isosurface $=0.02 \mathrm{au})$ 

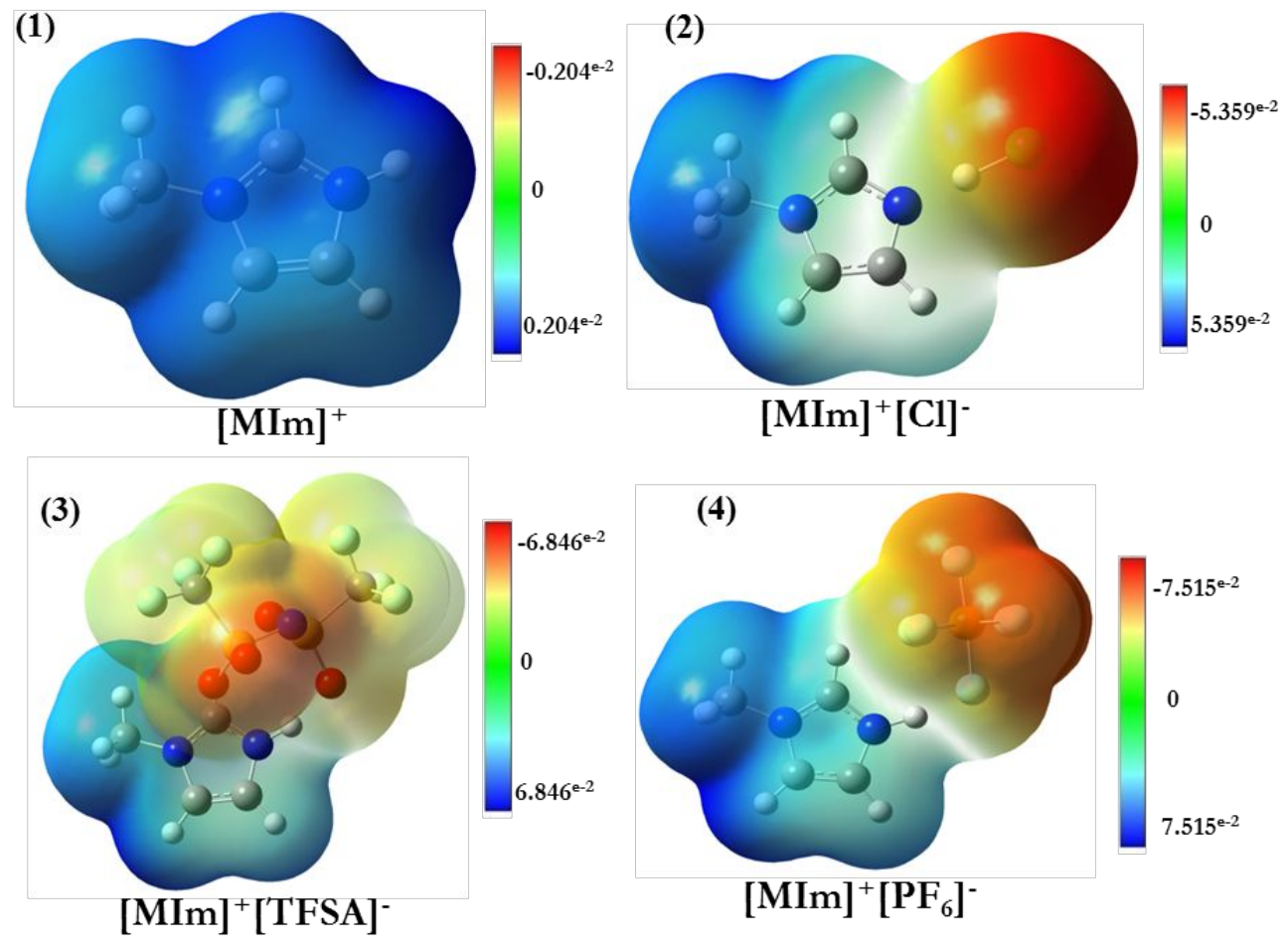

Figure S2. Electroststic potential maps (isovalue $0.02 \mathrm{a.u}$ ) of (1) $[\mathrm{MIm}]^{+}$, (2) $[\mathrm{MIm}]^{+}[\mathrm{Cl}]^{-},(3)[\mathrm{MIm}]^{+}$ [TFSA]', (4) $[\mathrm{MIm}]^{+}\left[\mathrm{PF}_{6}\right]^{-}$. 

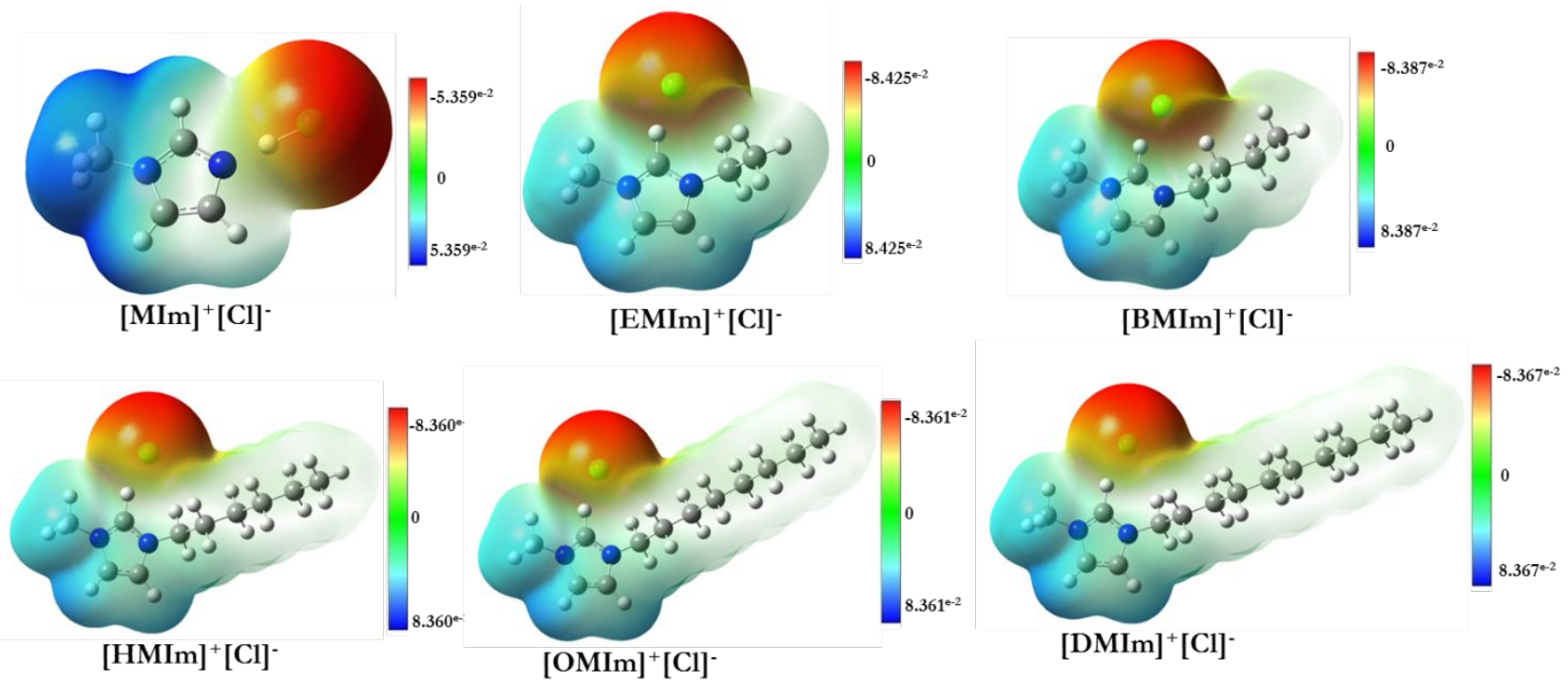

Figure S3. Electrostatic potential $(\mathrm{ESP})$ map (isosurface value $=0.02 \mathrm{au}$ ) of the $\left[\mathrm{C}_{\mathrm{n}} \mathrm{MIm}\right]^{+}[\mathrm{Cl}]^{-} \mathrm{ILs}$ at the $\mathrm{PBE}+\mathrm{D} 3 / 6-311++\mathrm{G}^{* *}$ level of theory. 


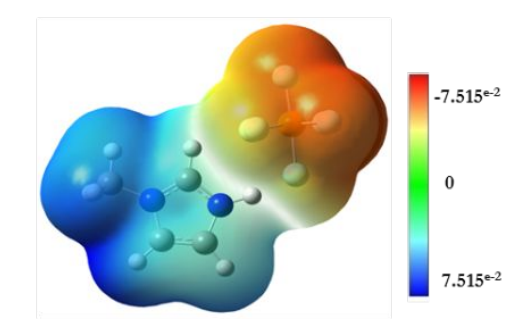

$[\mathrm{MIm}]^{+}\left[\mathrm{PF}_{6}\right]^{-}$

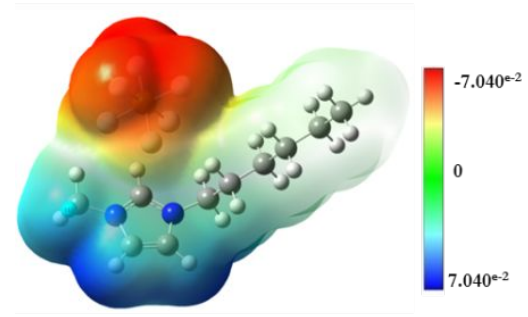

$[\mathrm{HMIm}]^{+}\left[\mathrm{PF}_{6}\right]^{-}$
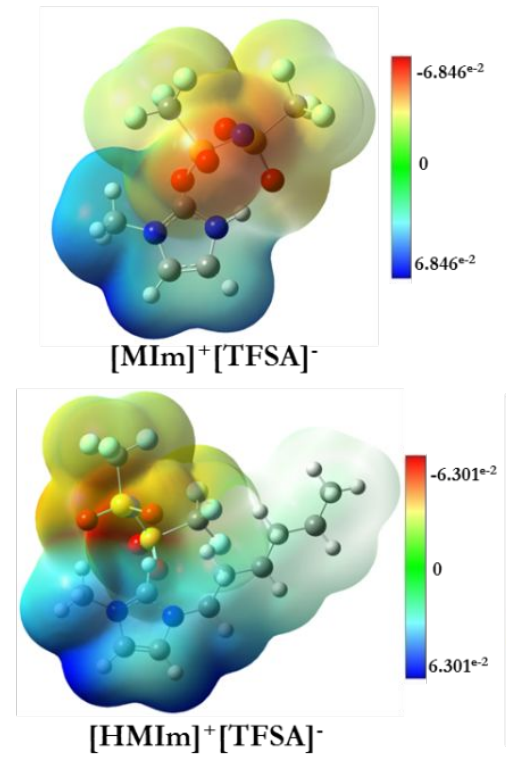

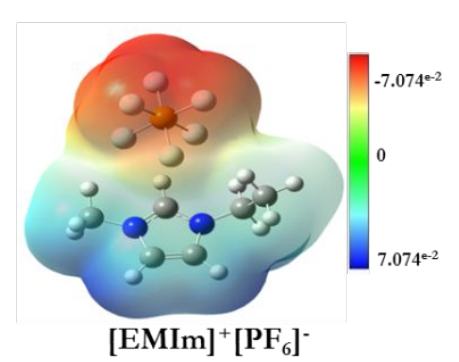

$[\mathrm{EMIm}]^{+}\left[\mathrm{PF}_{6}\right]^{-}$
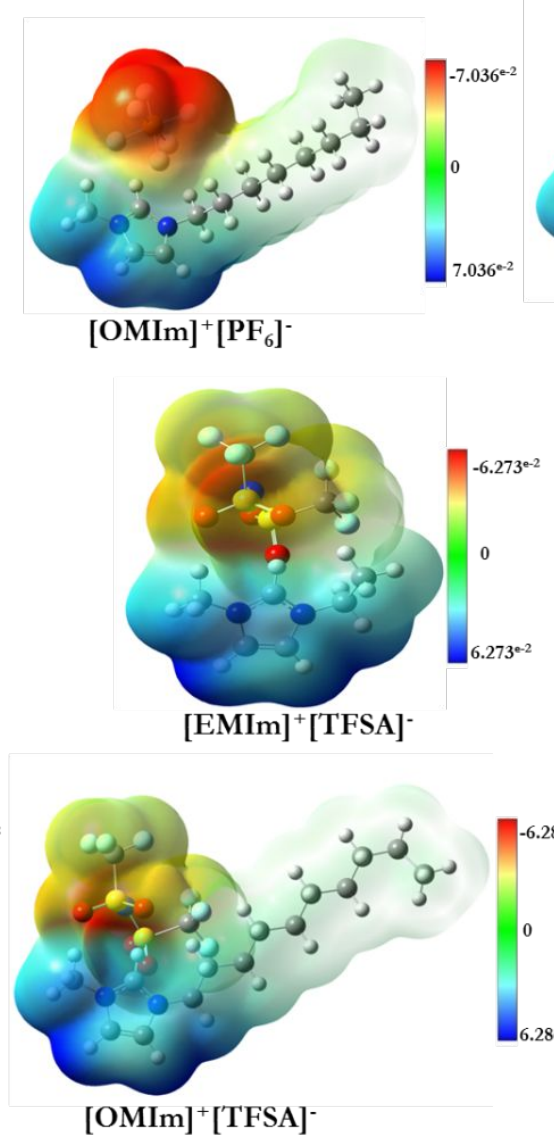
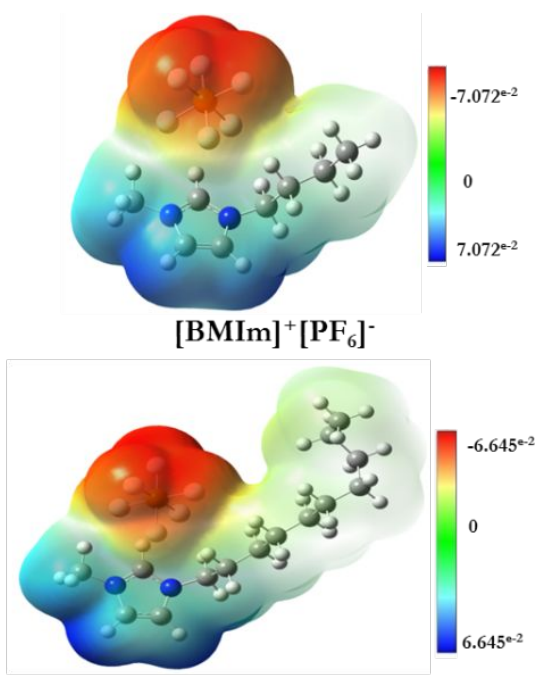

$[\mathrm{DMIm}]^{+}\left[\mathrm{PF}_{6}\right]^{-}$
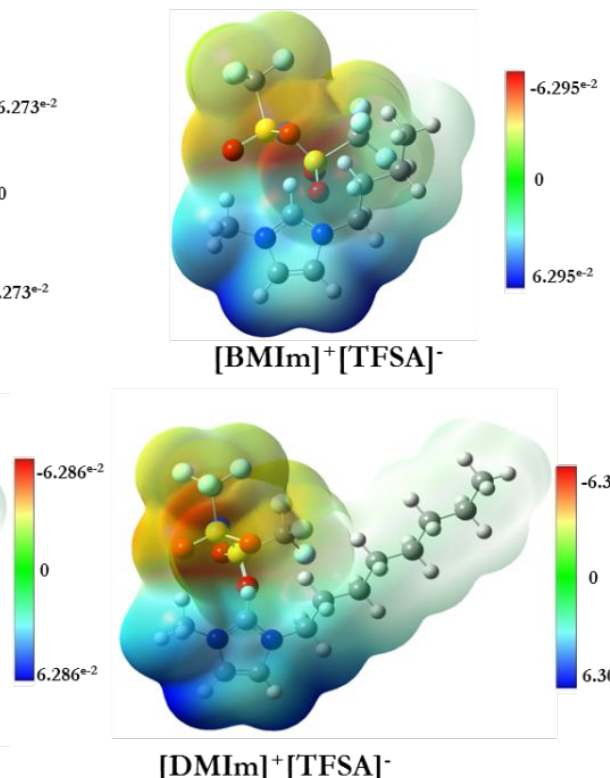

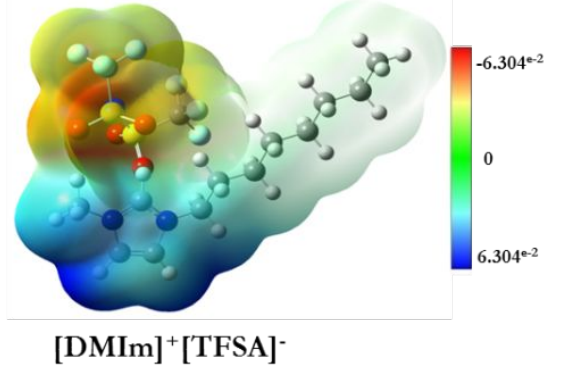

$[\mathrm{DMIm}]^{+}\left[\mathrm{TFSA}^{-}\right.$

Figure S4. The electrostatic potential (ESP) map (isosurface value $=0.02 \mathrm{au}$ ) of the $\left[\mathrm{C}_{\mathrm{n}} \mathrm{MIm}\right]^{+}\left[\mathrm{PF}_{6}\right]^{-} \mathrm{ILs}$ and [TFSA] $]^{-}$at the PBE+D3/6-311++G** level of theory. 

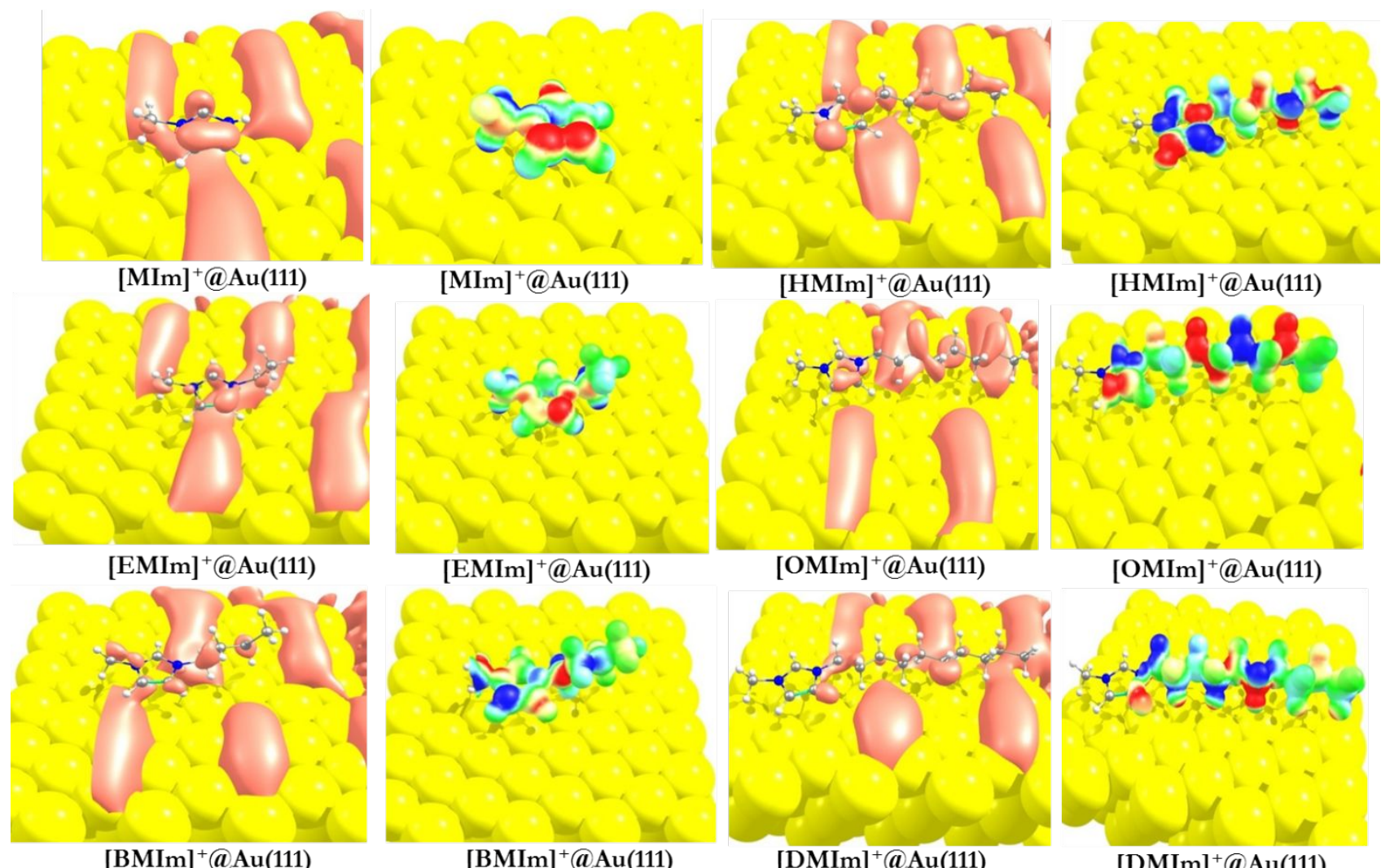

[HMIm] $]^{+} @ \mathrm{Au}(111)$
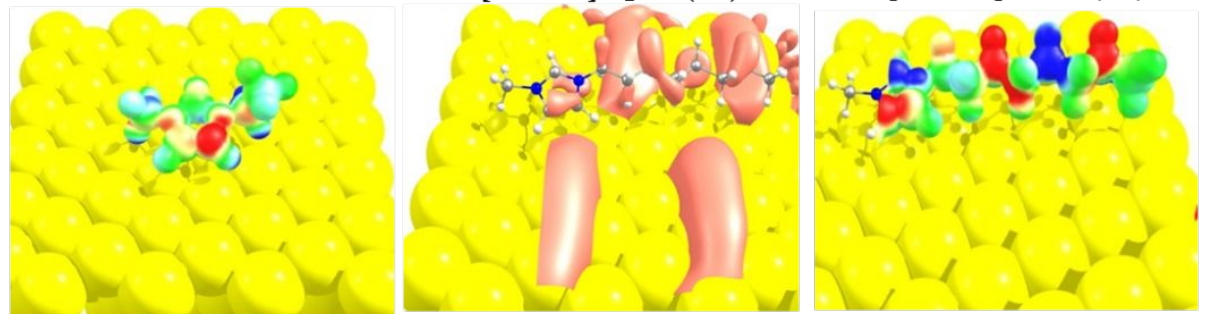

[EMIm] $]^{+}$Au(111)

$[\mathrm{OMIm}]^{+} @ \mathrm{Au}(111)$

[OMIm] $]^{+} @ \mathrm{Au}(111)$

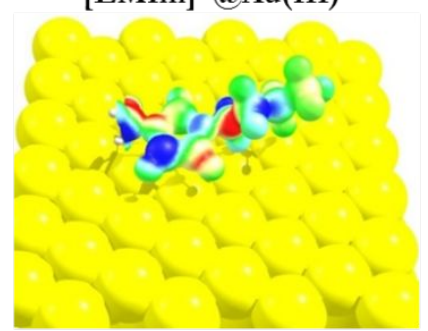

[BMIm] $]^{+}$Au(111)

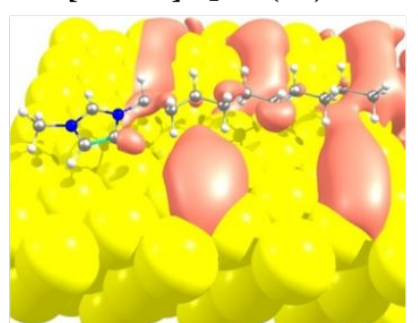

$[\mathrm{DMIm}]^{+} @ \mathrm{Au}(111)$

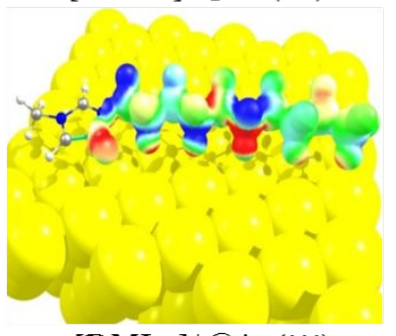

[DMIm] $@$ @Au(111)

Figure S5. Electron density maps of $\left[\mathrm{C}_{\mathrm{n}} \mathrm{MIm}\right]^{+} @ \mathrm{Au}(111)$ The blue and red colors represent the charge accumulation and depletion, respectively. For each compounds, the left image is the isosurface value at $0.001 \mathrm{au}$ and the right one is the sphere value at mapped at $0.001 \mathrm{au}$. 

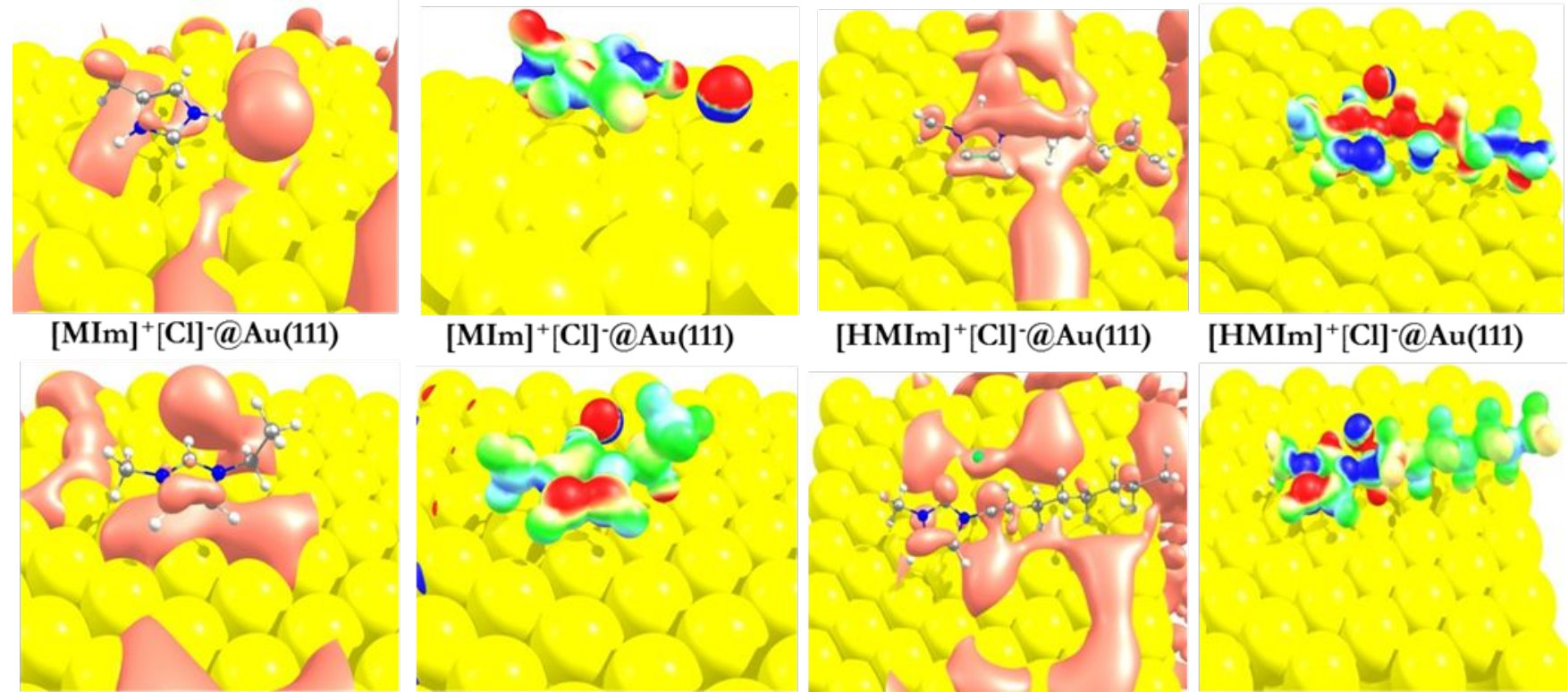

$[\mathrm{MIm}]^{+}[\mathrm{Cl}]^{-} @ \mathrm{Au}(111)$

[HMIm] $]^{+}[\mathrm{Cl}]^{-} @ A u(111)$

[HMIm] $]^{+}[\mathrm{Cl}]^{-@ A u(111) ~}$

[EMIm] $^{+}[\mathrm{Cl}]{ }^{-@ A u(111)}$
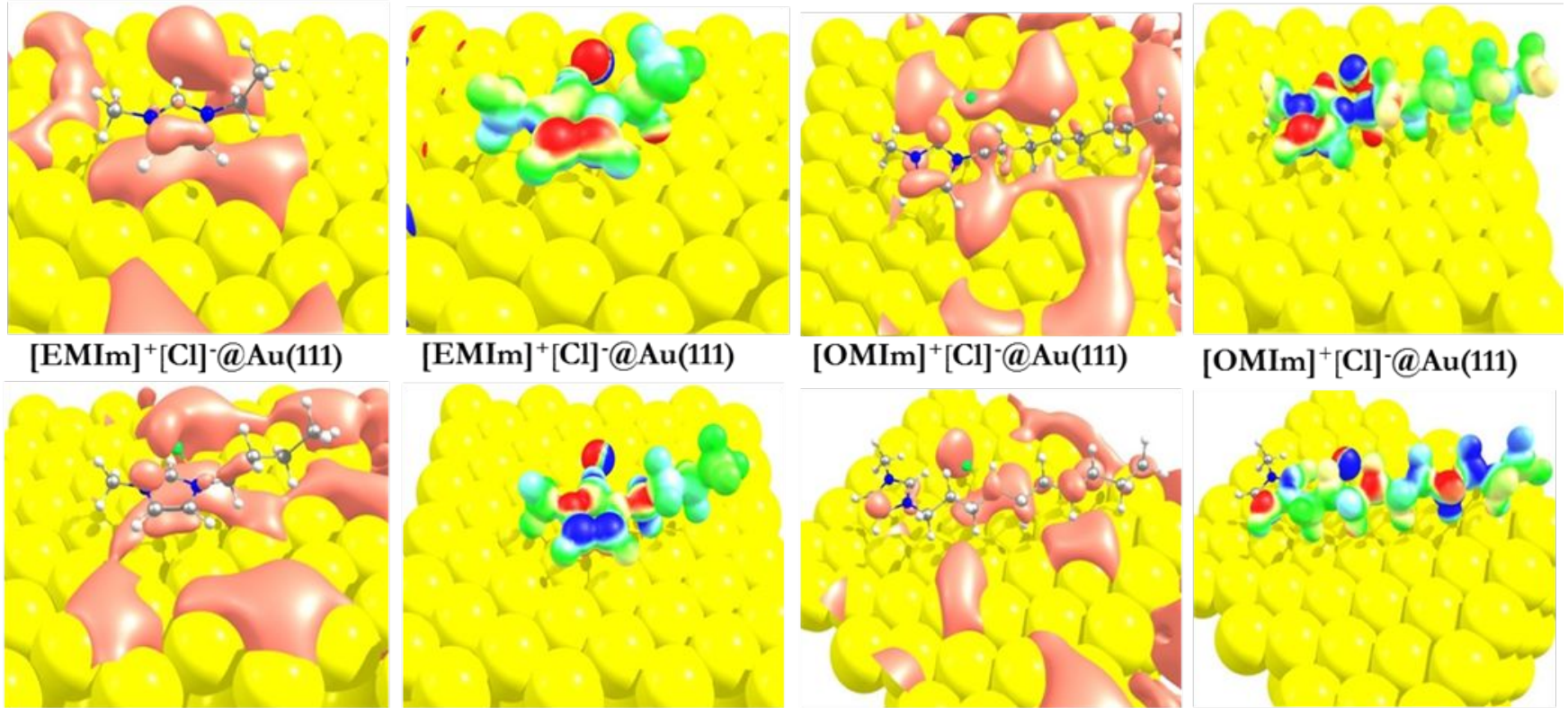

[OMIm] $^{+}[\mathrm{Cl}]^{-} @ \mathrm{Au}(111)$

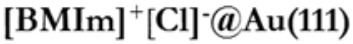

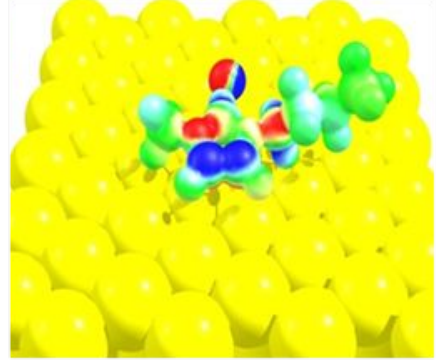

[BMIm] $^{+}[\mathrm{Cl}]^{-} @ \mathrm{Au}(111)$

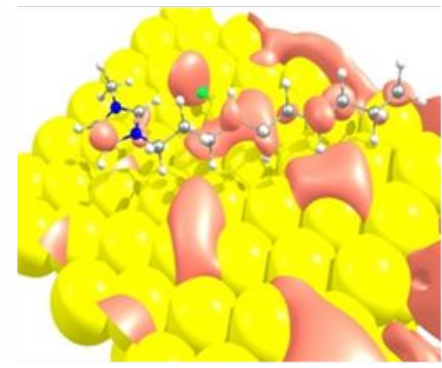

[DMIm] $^{+}[\mathrm{Cl}]^{-@ A u(111)}$

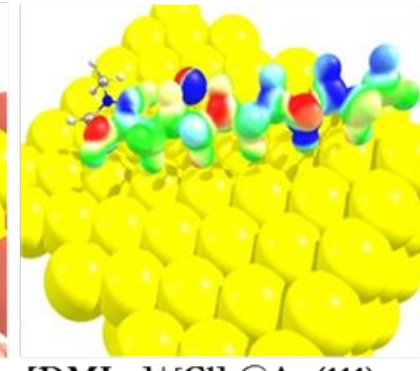

[DMIm] $^{+}[\mathrm{Cl}]^{-} @ \mathrm{Au}(111)$

Figure S6. Electron density maps of $\left[\mathrm{C}_{\mathrm{n}} \mathrm{MIm}\right]^{+}[\mathrm{Cl}]^{-} @ \mathrm{Au}(111)$. The blue and red colors represent the charge accumulation and depletion, respectively. For each compounds, the left image is the isosurface value at $0.001 \mathrm{au}$ and the right one is the sphere value at mapped at $0.001 \mathrm{au}$. 

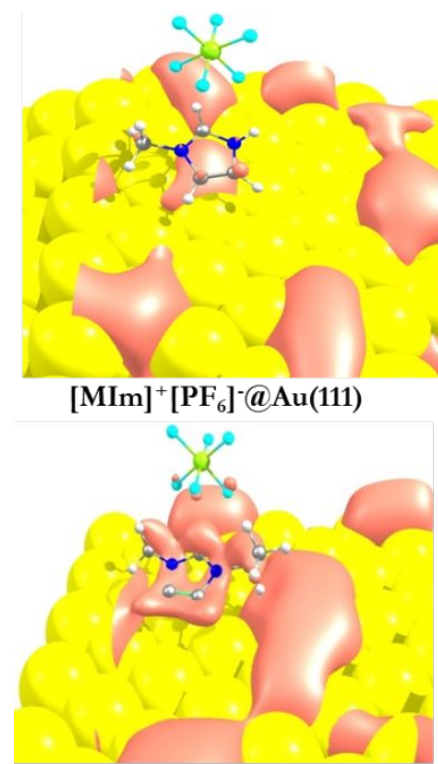

$[\mathrm{EMIm}]^{+}\left[\mathrm{PF}_{6}\right]^{-} @ \mathrm{Au}(111)$

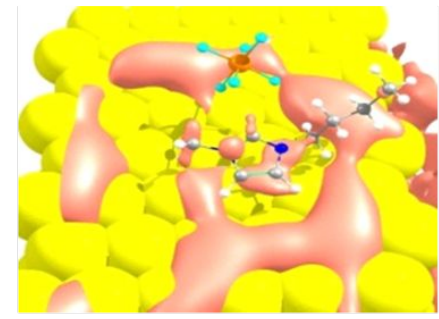

$[\mathrm{BMIm}]^{+}\left[\mathrm{PF}_{6}\right]^{-} @ \mathrm{Au}(111)$

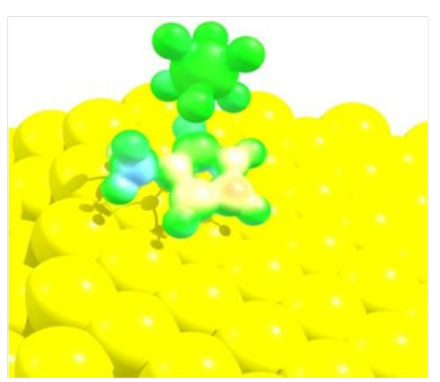

$[\mathrm{MIm}]^{+}\left[\mathrm{PF}_{6}\right]^{-} @ \mathrm{Au}(111)$

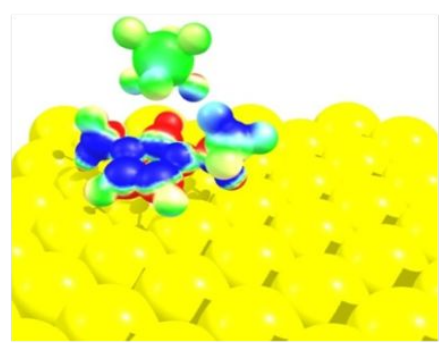

$[\mathrm{EMIm}]^{+}\left[\mathrm{PF}_{6}\right]^{-} @ \mathbf{A u}(111)$

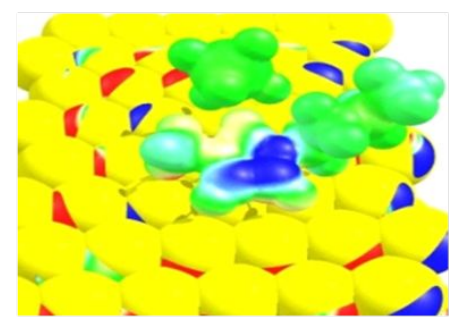

$[\mathrm{BMIm}]^{+}\left[\mathrm{PF}_{6}\right]^{-} @ \mathrm{Au}(111)$

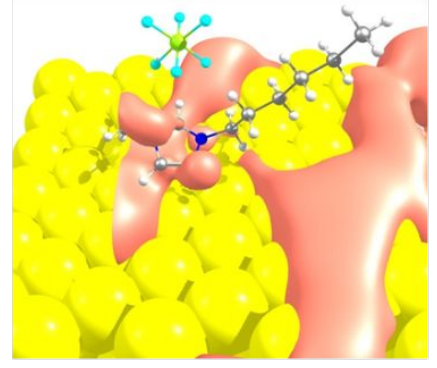

$[\mathrm{HMIm}]^{+}\left[\mathrm{PF}_{6}\right]^{-} @ \mathrm{Au}(111)$

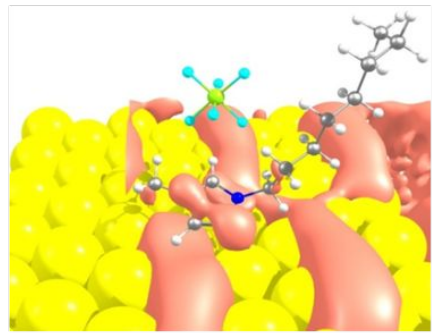

$[\mathrm{OMIm}]^{+}\left[\mathrm{PF}_{6}\right]^{-} @ \mathrm{Au}(111)$

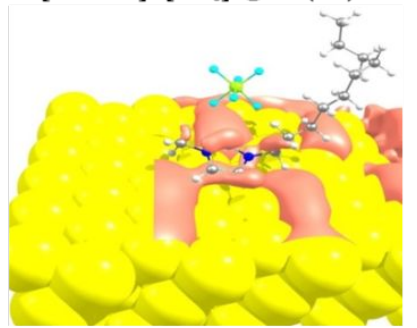

$[\mathrm{DMIm}]^{+}\left[\mathrm{PF}_{6}\right]^{-} @ \mathrm{Au}(111)$

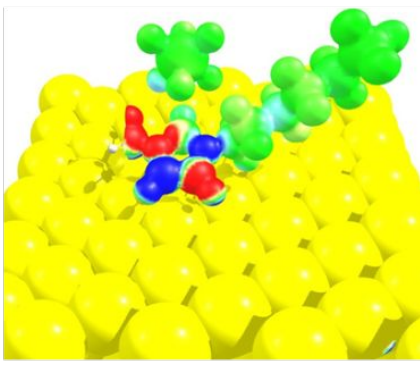

$[\mathrm{HMIm}]^{+}\left[\mathrm{PF}_{6}\right]^{-} @ \mathrm{Au}(111)$
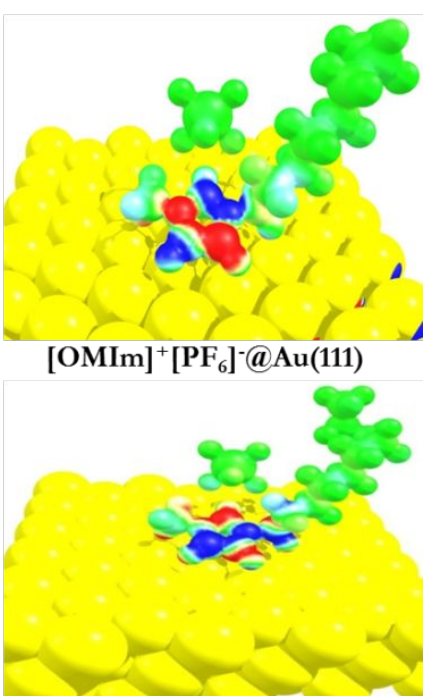

$[\mathrm{DMIm}]^{+}\left[\mathrm{PF}_{6}\right]^{-} @ \mathrm{Au}(111)$

Figure S7. Electron density maps of $\left[\mathrm{C}_{n} \mathrm{MIm}\right]^{+}\left[\mathrm{PF}_{6}\right]^{-} @ \mathrm{Au}(111)$. The blue and red colors represent the charge accumulation and depletion, respectively. For each compounds, the left image is the isosurface value at $0.001 \mathrm{au}$ and the right one is the sphere value at mapped at $0.001 \mathrm{au}$. 


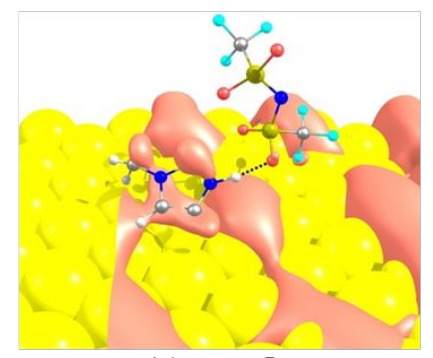

$[\mathrm{MIm}]^{+}[$TFSA] $@$ @Au(111)

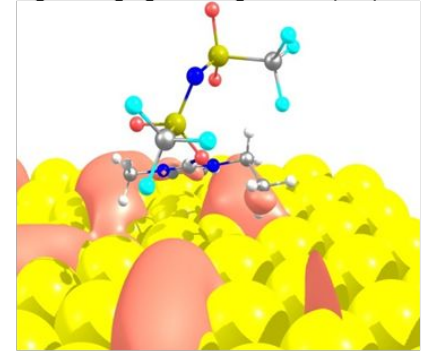

[EMIm] $]^{+}[$TFSA]-@Au(111)

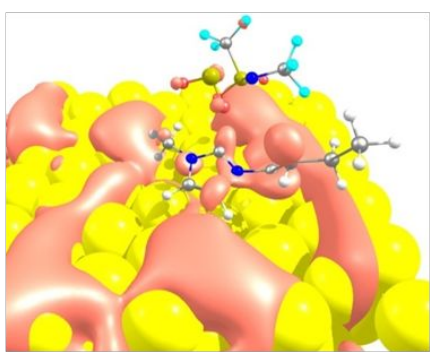

$[\mathrm{BMIm}]^{+}[\mathrm{TFSA}]^{-} \mathrm{a} \mathbf{A u ( 1 1 1 )}$

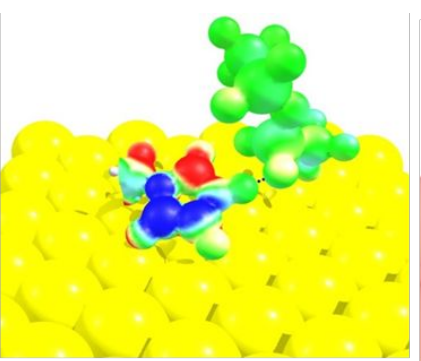

$[\mathrm{MIm}]^{+}[\mathrm{TFSA}]^{-} @ \mathrm{Au}(111)$

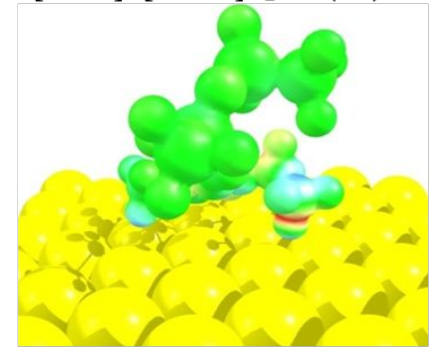

$[\mathrm{EMIm}]^{+}[\mathrm{TFSA}]^{-@ A u(111)}$

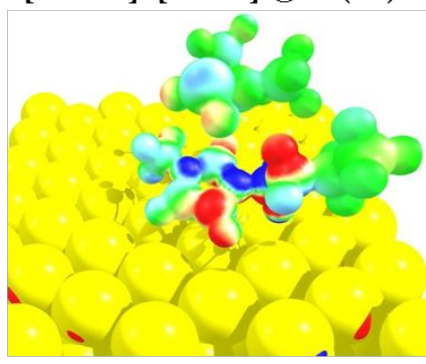

[BMIm] ${ }^{+}[\text {TFSA] }]^{-}$Au(111)

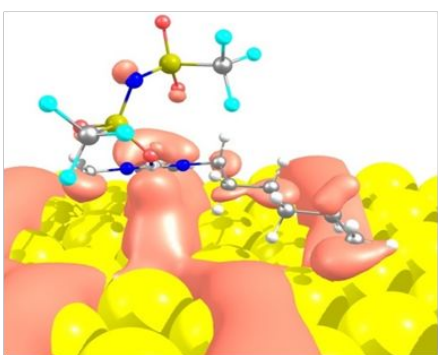

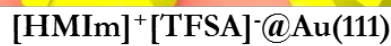

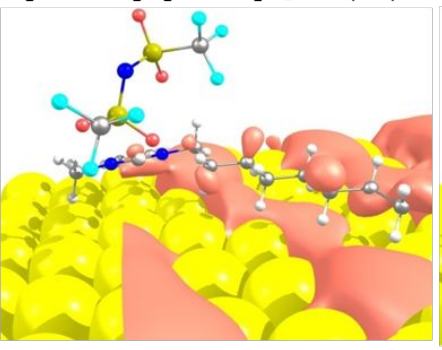

[OMIm]+[TFSA]-@Au(111)

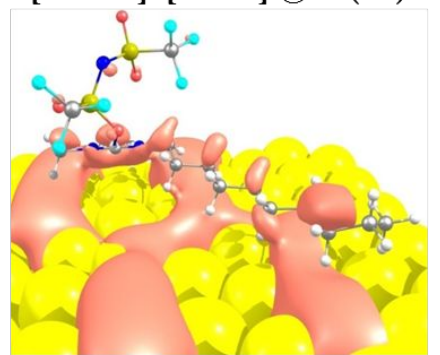

[DMIm] ${ }^{+}[\mathrm{TFSA}]^{-} @ \mathrm{Au}(111)$

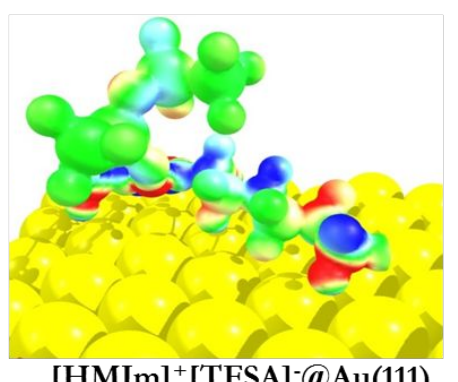

[HMIm]+[TFSA]-@Au(111)

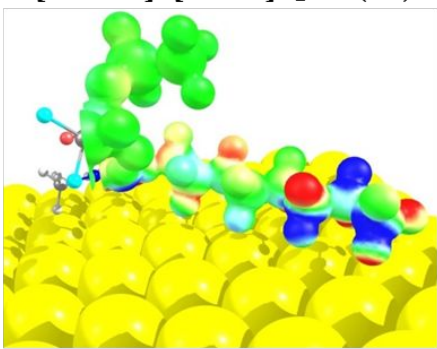

[OMIm] ${ }^{+}[\mathrm{TFSA}]^{-@ A u(111)}$

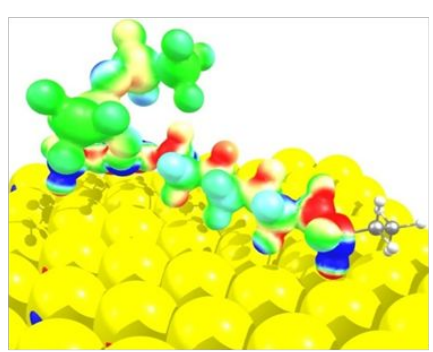

$[\mathrm{DMIm}]^{+}\left[\mathrm{TFSA}^{-} @ \mathrm{Au}(111)\right.$

Figure S8. Electron density maps of $\left[\mathrm{C}_{\mathrm{n}} \mathrm{MIm}\right]^{+}[\mathrm{TFSA}]^{-} @ \mathrm{Au}(111)$. The blue and red colors represent the charge accumulation and depletion, respectively. For each compounds, the left image is the isosurface value at $0.001 \mathrm{au}$ and the right one is the sphere value at mapped at $0.001 \mathrm{au}$. 